\title{
HUBUNGAN ANTARA AKTIVITAS FISIK DENGAN LINGKAR PINGGANG PADA SISWA OBES SENTRAL
}

\author{
Maria Elisabeth Adeline Ra Pati Tiala \\ George N. Tanudjaja \\ Sonny J. R. Kalangi
}

\author{
Bagian Anatomi Histologi Fakultas Kedokteran Universitas Sam Ratulangi \\ Email: adelinealin@yahoo.de
}

\begin{abstract}
Background. Obesity has become a worldwide problem. Obesity is caused by energy intake that is greater than energy expenditure. Physical activity is one of energy expenditure. Measuring waist circumference is a method that frequently done to determine obesity. Physical activity can reduce waist circumference regarding decreased body fat percentage especially in visceral fat. Objective. This research was aimed to know the relationship between physical activity and waist circumference in central obese students. Method. An observational method with cross sectional design research was done in November and December 2012 in Saint Ignatius Catholic High School Malalayang Manado. Global Physical Activity Questionnaire (GPAQ) is used in measuring physical activity. Waist circumference was measured with OneMed tape. The analysis used Spearman correlation test. Result. The waist circumferences of 61 respondents were in central obesity. The lowest value of Metabolic Energy Turnover (MET) was 900 MET-minutes/week and the highest was 2,900 MET-minutes/week. In 10 men respondents, the smallest waist circumference was $90.2 \mathrm{~cm}$ and the biggest was $110.5 \mathrm{~cm}$. In 51 women respondents, the smallest waist circumference was $80.3 \mathrm{~cm}$ and the biggest was $99.0 \mathrm{~cm}$. Conclusion. There was no significant relationship between physical activity and waist circumference $(p=0,077)$.
\end{abstract}

Keyword: physical activity, waist cifcumference, obesity, central obese.

\begin{abstract}
Abstrak: Latar Belakang. Obesitas menjadi masalah di seluruh dunia. Obesitas disebabkan karena masukan energi melebihi penggunaan energi. Aktivitas fisik ialah salah satu penggunaan energi. Cara yang sering digunakan untuk menentukan obesitas yaitu dengan mengukur lingkar pinggang. Aktivitas fisik mampu menurunkan ukuran lingkar pinggang karena berkaitan dengan penurunan persentase lemak tubuh terutama lemak viseral. Tujuan. Penelitian ini bertujuan untuk mengetahui hubungan antara aktivitas fisik dengan lingkar pinggang pada siswa obes sentral. Metode. Penelitian observasional dengan desain cross sectional dilaksanakan pada Bulan November sampai Desember 2012 di SMA Katolik Santo Ignatius Malalayang Manado. Pengukuran aktivitas fisik menggunakan kuesioner Global Physical Activity Questionnaire (GPAQ). Lingkar pinggang diukur dengan pita ukur OneMed. Analisis menggunakan uji korelasi Spearman. Hasil. Sebanyak 61 responden mempunyai lingkar pinggang dengan obes sentral. Nilai Metabolic Energy Turnover (MET) terendah ialah 900 MET-menit/minggu dan tertinggi ialah 2.900 MET-menit/minggu. Pada 10 responden laki-laki, lingkar pinggang paling kecil yaitu 90,2 cm dan paling besar 110,5 cm. Pada 51 responden perempuan, lingkar pinggang paling kecil ialah $80,3 \mathrm{~cm}$ dan paling besar ialah 99,0 $\mathrm{cm}$. Simpulan. Tidak terdapat hubungan yang signifikan antara aktivitas fisik dengan lingkar pinggang $(\mathrm{p}=0,077)$.
\end{abstract}

Kata kunci: aktivitas fisik, lingkar pinggang, obesitas, obes sentral. 
Dewasa ini, obesitas menjadi masalah di seluruh dunia. Hal tersebut disebabkan karena prevalensi obesitas yang meningkat. ${ }^{1}$ Peningkatan prevalensi obesitas pada anak-anak dan remaja sejajar dengan orang dewasa. $^{2}$

Obesitas menjadi masalah kesehatan di Indonesia terutama di kota-kota besar. ${ }^{1,3}$ Pada tahun 2004, prevalensi obesitas anak Sekolah Dasar (SD) di beberapa kota besar seperti Medan, Padang, Jakarta, Surakarta, Yogyakarta, Surabaya dan Manado berkisar 2,1\%-25\%. ${ }^{3}$ Prevalensi obesitas pada remaja di Indonesia yaitu sebesar 9,7\% di Yogyakarta, sebesar 10,6\% di Semarang dan sebesar 15,8\% di Denpasar. ${ }^{4}$ Menurut data Riset Kesehatan Dasar (Riskesdas) tahun 2007, prevalensi obesitas penduduk Indonesia berusia 15 tahun ke atas sebesar $10,3 \%{ }^{5}$

Obesitas umumnya disebabkan karena masukan energi melebihi penggunaan energi oleh tubuh yaitu untuk kepentingan metabolisme basal, aktivitas fisik, pembuangan sisa makanan dan pertumbuhan. Kelebihan energi yang dikonsumsi tanpa disertai penggunaan energi yang memadai akan menyebabkan peningkatan penyimpanan energi dalam sel lemak yang berakibat meningkatnya jumlah dan ukuran sel lemak. Keadaan ini yang mengakibatkan obesitas. $^{6}$

Perkembangan teknologi, media elektronik dan gaya hidup sedentary menjadi penyebab berkurangnya aktivitas fisik sehingga terjadi penurunan keluaran energi. Perilaku kehidupan modern yang merujuk pada pola makan tinggi kalori, lemak dan kolesterol juga berdampak meningkatkan risiko obesitas. ${ }^{3,7,8}$ Selain faktor perilaku dan lingkungan, faktor genetik juga ikut berperan pada timbulnya obesitas. ${ }^{2,7,9}$

Saat ini, cara yang sering digunakan untuk mengukur obesitas yaitu dengan Indeks Masa Tubuh (IMT) dan lingkar pinggang. ${ }^{10}$ Lingkar pinggang menjadi indikator yang lebih kuat terhadap faktor risiko kardiometabolik dibandingkan dengan IMT. Hal tersebut berkaitan dengan distribusi lemak pada tubuh. ${ }^{11}$
Aktivitas fisik mampu menurunkan ukuran lingkar pinggang karena berkaitan erat dengan penurunan persentase lemak tubuh terutama lemak viseral. ${ }^{12}$ Gaya hidup tidak aktif dan tingkat aktivitas yang rendah merupakan salah satu faktor utama terjadinya obesitas. Data Riskesdas pada tahun 2007 menunjukkan bahwa 48,2\% penduduk Indonesia yang berusia lebih dari sepuluh tahun kurang melakukan aktivitas fisik. $^{12}$

Ahli epidemiologi menyebutkan kurangnya aktivitas fisik sebagai salah satu faktor terhadap peningkatan obesitas pada anak dan remaja dalam kurun waktu 20 tahun terakhir. Terdapat hubungan yang jelas antara komposisi tubuh dengan aktivitas fisik. ${ }^{13}$ Komposisi tubuh dapat ditentukan berdasarkan ukuran lingkar pinggang, Penelitian ini dilakukan untuk mengetahui hubungan antara aktivitas fisik dengan lingkar pinggang pada siswa obes sentral.

\section{METODE PENELITIAN}

Penelitian ini merupakan penelitian observasional-analitik dengan desain cross sectional untuk mengetahui hubung-an antara aktivitas fisik dengan lingkar pinggang pada siswa obes sentral. Penelitian dilaksanakan pada Bulan November dan Desember 2012 di SMA Katolik Santo Ignatius Malalayang Manado. Kriteria inklusi pada penelitian ini yaitu seluruh siswa SMA Katolik Santo Ignatius Malalayang Manado yang obes sentral ( $\geq$ persentil 90 yaitu $\geq 81 \mathrm{~cm}$ untuk laki laki dan $\geq 72 \mathrm{~cm}$ untuk perempuan), tidak mengalami asites dan bersedia untuk berpartisipasi. Kriteria eksklusi pada penelitian ini yaitu responden yang mengalami gangguan fisik sehingga tidak dapat melakukan aktivitas fisik dengan baik. Instrumen penelitian yang digunakan yaitu kuesioner aktivitas fisik GPAQ, pita ukur One Med dengan ketelitian $0,1 \mathrm{~cm}$, alat tulis menulis dan program Statistical Package for Social Science (SPSS) versi 19. Uji statistik yang digunakan adalah uji korelasi Spearman. 
Tiala, Tanudjaja, Kalangi; Hubungan antara Aktivitas Fisik dengan Lingkar Pinggang... 457

\section{HASIL DAN PEMBAHASAN}

\section{Hasil}

\section{Jumlah responden}

Penelitian dilakukan di SMA Katolik Santo Ignatius Malalayang pada 160 siswa yang terdiri dari 72 responden laki-laki dan 88 responden siswa perempuan. Sebanyak 61 responden dari total 160 responden mempunyai lingkar pinggang masuk dalam kelompok obesitas sentral yang dapat dilihat pada tabel 1. Terdapat 61 responden (38,125\%) yang berlingkar pinggang termasuk dalam kelompok obesitas sentral sedangkan yang tidak termasuk dalam kelompok obesitas sentral sebanyak 99 responden (61,875\%) dari total 160 responden.

Tabel 1. Kelompok tidak obesitas sentral dan obesitas sentral.

\begin{tabular}{ccc}
\hline \multirow{2}{*}{ Kelompok } & \multicolumn{2}{c}{ Jumlah } \\
\cline { 2 - 3 } & $\mathbf{n}$ & $\mathbf{\%}$ \\
\hline Tidak obesitas sentral & 99 & $61,875 \%$ \\
Obesitas sentral & 61 & $38,125 \%$ \\
\hline \multicolumn{1}{c}{ Total } & 160 & $100 \%$ \\
\hline
\end{tabular}

\section{Karakteristik responden berdasarkan usia}

Berdasarkan penelitian yang telah dilakukan pada 61 responden obes sentral didapatkan distribusi usia yang disajikan pada tabel 2. Terdapat 11 responden (18\%) berusia 14 tahun. Sebanyak 28 responden (45,9\%) berusia 15 tahun. Modus usia responden yaitu 15 tahun. Responden yang berusia 16 tahun sebanyak 10 responden (16,4\%) dan usia 17 tahun yaitu 11 responden (18\%). Paling sedikit yaitu satu responden $(1,7 \%)$ berada pada usia 18 tahun.

Responden paling muda berusia 14 tahun sedangkan responden dengan usia paling tua yaitu 18 tahun. Rerata usia dari total 61 responden yaitu 15,39 tahun dengan standar deviasi 1,037 tahun.
Tabel 2. Karakteristik responden berdasarkan usia.

\begin{tabular}{ccc}
\hline \multirow{2}{*}{ Usia (tahun) } & \multicolumn{3}{c}{ Jumlah } \\
\cline { 2 - 3 } & $\mathbf{n}$ & $\mathbf{\%}$ \\
\hline 14 & 11 & 18 \\
15 & 28 & 45,9 \\
16 & 10 & 16,4 \\
17 & 11 & 18 \\
18 & 1 & 1,7 \\
\hline Total & 61 & $100 \%$ \\
\hline
\end{tabular}

\section{Karakteristik responden berdasarkan jenis kelamin}

Terdapat 10 responden (16,4\%) yang berjenis kelamin laki-laki sedangkan yang berjenis kelamin perempuan ada 51 responden $(83,6 \%)$ dari total keseluruhan 61 responden yang termasuk dalam kriteria obesitas sentral. Distribusi berdasarkan jenis kelamin dapat dilihat pada tabel 3 .

Tabel 3. Karakteristik responden obesitas berdasarkan jenis kelamin.

\begin{tabular}{lcc}
\hline \multirow{2}{*}{ Jenis kelamin } & \multicolumn{2}{c}{ Jumlah } \\
\cline { 2 - 3 } & $\mathbf{n}$ & $\mathbf{\%}$ \\
\hline Laki-laki & 10 & 16,4 \\
Perempuan & 51 & 83,6 \\
\hline \multicolumn{1}{c}{ Total } & 61 & $16,875 \%$ \\
\hline
\end{tabular}

\section{Aktivitas fisik}

Aktivitas fisik yang dilakukan oleh 61 responden ini termasuk dalam level sedang yaitu nilai MET dalam rentang $\geq 600$-2999 MET-menit/minggu yang dapat dilihat pada tabel 4. Tiga responden (4,9\%) dalam rentang nilai ME6D0 -999 METmenit/minggu. Sebanyak 38 responden (62,29\%) dalam rentang nilai MET $\geq 1000$ 1999 MET-menit/minggu sedangkan untuk rentang nilai MEsD000 -2999 METmenit/minggu ada 20 responden (32,79\%).

Hasil penelitian menunjukkan dari total 61 responden, didapat nilai MET terendah adalah 900 MET-menit/minggu sedangkan nilai MET tertinggi adalah 2900 MET-menit/minggu. Rerata yang didapat adalah 1779,02 MET-menit/minggu dengan 
standar deviasi 590,970 MET-menit/ minggu.

Tabel 4. Aktifitas fisik berdasarkan nilai MET.

\begin{tabular}{ccc}
\hline \multirow{2}{*}{$\begin{array}{c}\text { Nilai MET } \\
\text { (MET-menit/minggu) }\end{array}$} & \multicolumn{2}{c}{ Jumlah } \\
\cline { 2 - 3 } $\mathbf{n}$ & $\mathbf{\%}$ \\
\hline$\geq 600-999$ & 3 & $4,92 \%$ \\
$\geq 1000-1999$ & 38 & $62,29 \%$ \\
$\geq 2000-2999$ & 20 & $32,79 \%$ \\
\hline Total & 61 & $100 \%$ \\
\hline
\end{tabular}

\section{Lingkar Pinggang}

Hasil pengukuran lingkar pinggang yaitu pada 10 responden laki-laki, lingkar pinggang paling kecil ialah 90,2 $\mathrm{cm}$ dan paling besar 110,5 $\mathrm{cm}$. Pada 51 responden perempuan, lingkar pinggang paling kecil ialah 80,3 cm dan paling besar adalah 99,0 $\mathrm{cm}$. Rerata lingkar pinggang responden laki-laki ialah 94,163 cm sedangkan pada responden perempuan $84,247 \mathrm{~cm}$. Standar deviasi lingkar pinggang laki-laki ialah $7,4580 \mathrm{~cm}$ sedangkan perempuan $5,7179 \mathrm{~cm}$.

\section{Hubungan antara aktivitas fisik dengan lingkar pinggang pada siswa obes sentral}

Hasil uji Spearman yaitu nilai $\mathrm{p}=0,077$ $(p>\alpha)$ dan $r=-0,185$. Secara statistik tidak terdapat hubungan yang signifikan antara aktivitas fisik dengan lingkar pinggang pada siswa obes sentral $(\mathrm{p}=0,077)$.

\section{Pembahasan}

Aktivitas fisik diketahui berperan penting untuk mencegah obesitas dan memegang peranan terhadap distribusi lemak tubuh melalui penggunaan lemak dari daerah perut sebagai hasil redistribusi jaringan adiposa. ${ }^{14,15}$ Aktivitas fisik yang tidak adekuat menyebabkan semakin besarnya lemak tubuh yang ditimbun pada jaringan. ${ }^{1}$ Hasil penelitian menunjukkan tidak ada responden yang beraktivitas fisik $\geq 3000 \mathrm{MET}$-menit/minggu yaitu level berat.

Banyak faktor yang berkaitan dengan kurang aktifnya remaja yaitu gender, karakteristik fisiologis, kelas olahraga, menonton TV, musim, cuaca, keamanan lingkungan, pengaruh orang tua dan pengaruh teman sebaya. Gender dan karakteristik fisiologis merupakan faktor yang tidak dapat dirubah. Anak-anak dan remaja lebih banyak bermain di dalam rumah dibanding diluar rumah, misalnya bermain games komputer, menonton televisi maupun media elektronik lain ketimbang berjalan, bersepeda maupun naik-turun tangga. ${ }^{4}$

Jam menonton TV dan bermain video games per minggu akan mengurangi kesempatan remaja untuk berada di luar rumah. Klesges ${ }^{15}$ melaporkan persen waktu berada di luar rumah berhubungan erat dengan aktivitas fisik pada remaja. Secara tidak langsung menonton TV dan bermain video games mengurangi kesempatan remaja berada di luar rumah sehingga akan mengurangi juga kesempatan untuk beraktivitas fisik. Sebuah penelitan kohort memberikan hasil bahwa menonton TV lebih dari 5 jam dapat meningkatkan prevalensi obesitas pada anak usia 6 - 18 tahun sebesar $18 \%$. Staiano ${ }^{16}$ membuktikan bahwa menonton TV berkaitan dengan lingkar pinggang yang tinggi.

Hasil penelitian yang dilakukan sesuai dengan penelitian oleh Widhy Bodhy dan Aaltje A. Manampiring pada remaja di Kota Tomohon yaitu dari 35\% siswa yang menjadi responden yang mengalami obesitas sentral, persentase siswa laki-laki sebesar $11,7 \%$ dan siswa perempuan $24,2 \% .{ }^{17}$ Hal yang sama juga ditemukan pada penelitian Elya Sugianti, Hardinsyah dan Nurfi Afriansyah dimana prevalensi obesitas sentral lebih tinggi pada perempuan daripada laki-laki. ${ }^{18}$

Hal ini diduga karena cadangan lemak tubuh lebih banyak terdapat pada perempuan. ${ }^{18}$ Ikatan Dokter Anak Indonesia (IDAI) menegaskan bahwa anak laki-laki yang sedang tumbuh pesat penambahan jaringan otot lebih banyak daripada jaringan lemak secara proporsional, demikian pula massa tubuh tanpa lemak dibanding anak perempuan. Faktor lain yang mempengaruhi diantaranya etnis, onset pubertas, diet dan aktivitas fisik. ${ }^{19}$

Hasil penelitian didapat tidak terdapat 
hubungan bermakna signifikan antara aktivitas fisik dengan lingkar pinggang pada siswa obes sentral $(\mathrm{p}=0,077)$. Hasil yang didapat sejalan dengan penelitian yang dilakukan Susiana Candrawati yaitu tidak terdapat perbedaan yang bermakna secara statistik antara tingkat aktivitas fisik dengan lingkar pinggang $(p=1,000){ }^{12}$ Penelitian yang dilakukan oleh Elya Sugianti, Hardinsyah dan Nurfi Afriansyah menyatakan bahwa tidak terdapat perbedaan peluang seseorang mengalami obesitas sentral yang diukur berdasarkan lingkar pinggang menurut aktivitas fisik berat. ${ }^{18}$ Hasil penelitian yang dilakukan MS Anam dkk pada tahun 2009 yaitu tidak didapatkan pengaruh yang signifikan antara olahraga (aktivitas fisik) dan intervensi diet terhadap lemak tubuh. ${ }^{20}$

Tidak terdapatnya hubungan yang signifikan antara aktivitas fisik dengan lingkar pinggang pada siswa obes sentral dapat disebabkan karena beberapa faktor yang mempengaruhi kedua variabel. Beberapa faktor yaitu asupan gizi, besar keluarga, gaya hidup yaitu kebiasaan merokok, kondisi stres dan depresi. Hal yang mempengaruhi ketidakvalidan pengukuran aktivitas fisik menggunakan kuesioner diantaranya keakuratan dalam mengingat kembali aktivitas fisik yang dilakukan. ${ }^{21}$ Kemungkinan bias juga dapat terjadi karena subyektifitas responden dalam mengisi kuesioner aktivitas fisik. GPAQ yang mengukur aktivitas fisik selama tujuh hari sesuai kebiasaan ini belum tentu menggambarkan aktivitas fisik dalam jangka waktu lama.

\section{SIMPULAN}

Tidak terdapat hubungan signifikan antara aktivitas fisik dengan lingkar pinggang pada siswa obes sentral. Persentase obesitas sentral pada perempuan lebih besar dibandingkan pada laki-laki.

\section{UCAPAN TERIMA KASIH}

Penulis mengucapkan terima kasih kepada dr. A. S. L. Bolang, M.Kes, AIFO dan dr. Shane H. R. Ticoalu, M.Kes,AIFO atas segala saran dan perbaikan yang telah diberikan. Terima kasih juga disampaikan kepada Pastor Marcell Lintong, Pr dan SMA Katolik Santo Ignatius Malalayang Manado serta semua pihak yang baik secara langsung maupun tidak langsung telah menumbuhkan ide atau gagasan dalam pemikiran penulis serta membantu penulis menyelesaikan penelitian dan artikel ini.

\section{DAFTAR PUSTAKA}

1. Mexitalia M, Utari A, Sakundarno M, Yamauchi T, Subagio HW, Soemantri A. Sindroma metabolik pada remaja obesitas. Medika Media Indonesia. 2009;43:300-5.

2. Sartika RAD. Faktor risiko obesitas pada anak 5-15 tahun di Indonesia. Makara Kesehatan. 2011;15:37-43.

3. Hidayati SN, Hadi $H$, Lestariana W. Hubungan asupan zat gizi dan indeks masa tubuh dengan hiperlipidemia pada murid SLTP yang obesitas di Yogyakarta. Sari Pediatri. 2006;8:25-31.

4. Adityawarman, Mexitalia. Hubungan aktivitas fisik dengan komposisi tubuh pada remaja [artikel penelitian]. Semarang: Fakultas Kedokteran Universitas Diponegoro; 2007.

5. Badan Penelitian dan Pengembangan Depkes RI. Laporan hasil riset kesehatan dasar nasional tahun 2007. Jakarta: Departemen Kesehatan RI; 2007.

6. Sargowo D, Andarini S. The relationship between food intake and adolescent metabolic syndrome. Jurnal Kardiologi Indonesia. 2011;32:14-23.

7. Mustamin. Asupan energi dan aktivitas fisik dengan kejadian obesitas sentral pada ibu rumah tangga di Kelurahan Ujung Pandang Baru Kecamatan Tallo Kota Makassar. Media Gizi Pangan. Juli 2010;10:65.

8. Besson H, Ekelund U, Luan J, May AM, Sharp S, Travier N, et al. A crosssectional analysis of physical activity and obesity indicators in European participants of the EPIC-PANACEA study. International Journal of Obesity. 2009;33:497-506.

9. Liu G, Zhu H, Lagou V, Gutin B, 
Stallmann-Jorgensen IS, Treiber F, Dong Y, et al. FTO variant rs9939609 is associated with body mass index and waist circumference, but not with energy intake or physical activity in European and African-American youth. BMC Medical Genetics. 2010;11:57.

10. Hartono A. Terapi gizi dan diet rumah sakit (Edisi Kedua). Jakarta: EGC, 2006; p.173.

11. Lehto R, Ray C, Lahti-Koski M, Roos E. Health behaviors, waist circumference and waist-to-height ratio in children. European Journal of Clinical Nutrition. 2011;65:841-8.

12. Candrawati S. Hubungan tingkat aktivitas fisik dengan indeks massa tubuh (IMT) dan lingkar pinggang mahasiswa. The Soedirman Journal of Nursing. Juli 2011;6:112-8.

13. Aziiza F. Analisis aktivitas fisik, konsumsi pangan, dan status gizi dengan produktivitas kerja pekerja wanita di industri konveksi [skripsi]. Bogor: Program Studi Gizi Masyarakat dan Sumber Keluarga Fakultas Pertanian Institut Pertanian; 2008.

14. Anam MS. Pengaruh intervensi diet dan olahraga terhadap indeks masa tubuh, kesegaran jasmani, hsCRP dan profil lipid pada anak obesitas [tesis]. Semarang: Program Pasca Sarjana Magister Ilmu Biomedik dan Program Pendidikan Dokter Spesialis Ilmu Kesehatan Anak Fakultas Kedokteran Universitas Diponegoro;2010.

15. Rahmawati N. Aktivitas fisik, konsumsi makanan cepat saji (fastfood), dan keterpaparan media serta faktor-faktor lain yang berhubungan dengan kejadian obesitas pada siswa SD Islam Al-Azhar 1 Jakarta Selatan tahun 2009 [skripsi]. Jakarta: Fakultas Kesehatan Masyarakat Universitas Indonesia; 2009.

16. Staiano A, Harrington DM, Broyles S, Gupta AK, Katzmarzyk PT. Television, adiposity, and cardiometabolic risk in children and adolescents. American Journal of Preventive Medicine. 2013; 44(1):40-7.

17. Bodhy W, Manampiring AA. Prevalensi sindroma metabolik pada remaja di Kota Tomohon. Manado: Universitas Sam Ratulangi; 2011.

18. Sugianti E, Hardinsyah, Afriansyah N. Faktor risiko obesitas sentral pada orang dewasa di DKI. Jakarta: Analisis Lanjut Data Riskesdas;2007.

19. Ikatan Dokter Anak Indonesia (IDAI). Nutrisi pada remaja [homepage on the Internet]. Nodate [cited 2013 Jan 11]. Available from: http://www.idai.or.id/ remaja/print.asp?q=20117695121.

20. Anam MS, Mexitalia M, Widjanarko B, Pramono A, Susanto H, Subagio HW. Pengaruh intervensi diet dan olah raga terhadap indeks massa tubuh, lemak tubuh dan kesegaran jasmani pada anak obes. Sari Pediatri. 2010;12(1):36-41.

21. Bates $\mathbf{H}$. Daily Physical Activity for Children and Youth: a review and synthesis of the literature. Canada: Alberta Education, 2006; p.20. 